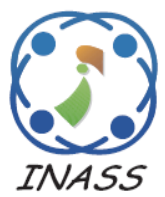

\title{
An Immune Memory and Negative Selection to Manage Tensions in Emergency Services
}

\author{
Mouna Berquedich ${ }^{1 *}$ \\ Oualid Kamach ${ }^{1}$ \\ Malek Masmoudi ${ }^{2}$ \\ ${ }^{1}$ Abdelmaleksaâdi University, Laboratory of Innovative Technologies (LTI), Tangier, Morocco \\ ${ }^{2}$ Jean Monnet University, Laboratory of Industrial Engineering, Roanne, France \\ * Corresponding author's Email: berquedich.mouna@ gmail.com
}

\begin{abstract}
The management of emergency services within hospitals typically requires an effective manipulation and capitalization of data sources comprising worth information useful for hospitals' security, safety and efficiency. To meet these requirements, we dispose an agile approach of decision-making that addresses massive crowds occurring at the emergency departments. This approach considers the major constraints that might face these departments, as such lacks of human resources, high costs, and confusedness of patient's prioritization cases, non-sufficient capacity and logistics. We, basically, inspired from the biological immune defence processes to illustrate a piloting emergency mean known as the artificial immune system (AIS). This system intelligently assists hospital's decisionmakers to enhance their supplying strategies, provides relevant traces from tracking previous information that assist hospital's staffs that face the massive patient flow, and fosters the execution of efficient solutions. This paper investigates AIS data and relevant traces of overcrowding dilemmas, in which these data could be exploited to increase the reception planning, decrease tension-related anomalies within the emergency department, and supplying hospital chiefs working under stress. The main objective is to present the basic concepts of a new approach that aims to provide hospital decision-makers with relevant traces to assist them in their decision-making in the difficult situations. The expected benefits (main findings) for using the considered approach are not only to provide crisis managers with a relevant computerized decision support system, but also to minimize financial costs, reduce the response time and positively impact the crisis management.
\end{abstract}

Keywords: Hospital environment, AIS, Negative selection, Clonal selection.

\section{Introduction}

Emergency services represent the critical parts and the most important infrastructures of a hospital. They experience fluctuated activities, and they are subjects of unpredictable or even exceptional situations. Unfortunately, the pediatric emergencies, which are organs of the emergency services, are not immune to this rule since they, yearly, confront periods of increase in patient flow, that are characterized by a peak of the activity. For instance, in the Hauts de France region, these periods were observed from November until February, and their peaks of activity were related to all viral infections, but, particularly, to the three annual viral epidemics that are: bronchiolitis, acute gastroenteritis and flux.
These situations, even if they cause a considerable mobilization of means, are not exceptional situations, i. e. an accident or an attack causing the outbreak of the white plan. However, they emergently concretize the important tensions in the emergency service within which the staffs need to either think about, anticipate, avoid or reduce their impact.

At present, there is a tendency towards an emergency service favouring complementarity and coordination of health actors. The vision consists associating an effective production management of care requiring hospital patients' flows control.

Nowadays, under the permanent demand of emergency medical care management of hospital emergency services, Emergency Department (ED) has become increasingly important. In this context, many scholars emphasize the advantages to combine 
intelligent systems to enhance the data availability, reliability, quality and accuracy of communication and computation in order to fully resolve overcrowding phenomenon within various hospitals' emergency facilities [5]. To anticipate and manage the patient outflow consists two of the most important dilemmas within emergency services worldwide. To deal with this patients' fluctuation, EDs require significant human, material resources and a high level of coordination among humans and materials [6]. Unfortunately, these resources are limited. The patients' flux generates ED overcrowding [6]. As a result, ED managers need to monitor patient flow continuously and detect either normal or abnormal patient behaviours. Hospital information system plays an important role in development hospitals efficiencies. To achieve that, we require a decision-making tool to control these situations.

The manipulation of data and the making of satisfying decisions are two major challenges facing the construction of hospital decision-support systems $[7,8]$. The objective lurking beneath that is to realize an excellent control of the patient's flow basing on experience feedback, which often consists a sitting of adverse events knowledge base. This feedback is articulated upon a starting loop collected from the ground; retrieving information, analysing it and finding appropriate solutions. After these analyses, it is possible to turn back to it, highlight suitable action to the emergency department, and, finally, deliver real retroactive loop of continuous updating from data fields.

The forthcoming sections in this paper structured as follows. The section 2 provides a review of literature concerning the disturbances, situation of tension and patient flows in emergency departments of hospitals, as well as citing many guiding principles of white plan and raising the reception capacities. Sections 3, 4 and 5 encapsulate the AIS techniques by describing they key features, analyzing of arrivals and treating patients in the emergency facilities, respectively. Sections 6 and 7 illustrate the filtering and the matching with Manhattan distance methodologies, followed by the system architecture and computational results in sections 8 and 9, respectively. Further, the conclusions and discussions presented in section 10 . In each case, the investigation resembles the most current works, describing key elements of the algorithm included, and shed light on the benefits and optimal results gained from the application of AIS technology-based means.

\section{Literature review}

\subsection{The disturbances in the hospital environment}

The emergency department is one of the critical infrastructures of a hospital [5]. Often, it confronts events and /or exceptional situations, as such the increasing number of patients resulting epidemic episodes (e.g. natural disasters, terrorist attacks and accidents, etc.), reduction of resources, and the appearance of complex pathologies requiring considerable time processing.

The consequences of these disturbances on the hospital emergency services can vary from a simple peak of activity to a situation of crisis, passing through situations of tension.

\subsection{The situation of tension in the emergency service}

The situation of tension in an emergency service refers to an imbalance between the load flow in care and the capacity of care [2]. The load flow in care quantified by the number of patients entering, the number of patients leaving and the number of patients abandoning emergencies without support. Whereas, the capacity for care (human and material resources) measured from the number of doctors and nurses or auxiliaries, and the number of boxes and beds and the medical equipment.

There are three main identified factors that can influence this balance between the load flow in care and the capacity of care. Firstly, factors influencing the number of admissions, as such seasonal epidemics (e.g. influenza, colds, gastroenteritis, bronchiolitis, etc.), seizures, availability of upstream and downstream doctors(on days, nights, or holidays).Secondly, the factors influencing the speed of management, and, therefore, the capacity to produce care, i.e. the speed of radiological examinations, the availability of resources. Finally, factors influencing downstream management, for example, internal and external transfer capacity, availability in downstream and outpatient care services.

Different perspectives have also outlined the situations of tension. They are bounded by different factors indeed. From a patient flow perspective, a tense situation in an emergency department refers to an imbalanced load out of the caring capacity of a facility, in which the marginal value exceeded. From these factors, the care load and the capacity of care depicted. Their definitions as follow:

1. Care load: basing on numbers of the entering and the outgoing patients, 
runaways and the number of untreated patients leaving emergency services.

2. The capacity of care: represents the emergency department patients' number being held during a given period, taking into account human and material means. This includes the number of doctors, nurses, and care auxiliaries, number of boxes, beds and medical equipment. It is estimated by emergency department employees.

Concerning the capacity of the care, we will define two types of capacity:

- The required capacity: the gain of the resource working with maximum capacity.

- Available Capacity: the capacity of the resource subtracting from the times of dysfunction.

The main factors that can affect balance are:

- The factors affecting the number of inflows (patient flows): seasonal epidemics (influenza, colds, gastroenteritis, bronchiolitis, etc.), accidents (works, factories and road accidents).

- The factors influencing faster care and, therefore, the capacity to produce cares, as such the nursing staff competencies (experience feedback, etc.), internal and external transfer capacity (availability of downstream care services).

\subsection{Large influx of injured people in hospital}

The hospitality of massive influx victims is taken into account by a recent ministerial circular, called White Plan. This plan displays arranging levels made in every public and private hospitalization facility (with or without emergencies from this facility). The guiding principle of the White Plan is to ensure an optimal reception of victims considering the safety of already hospitalized persons. A crisis unit is the basic structure of the White Plan. Accordingly, deciding planned formalized provisions in reflexing sheets: the establishment of reception points for victims, families, media, access to these points of reception, opportunities to increase the admission capacity of the institution, and the management of the deceased peoples.

\subsection{Guiding principles of the white plan}

The triggering event generates a large number of simultaneous victims. It had, for too long, engendered policies of simple transportation to the nearest health facility.
These "wild" made evacuations took place using personal cars or ambulances. They mostly moved the catastrophe from one place to another. Indeed, an unwarned and unprepared hospital was too often the cradle of what Huguenard described as "an improvisation, a sterile agitation, multiple and contradictory orders, useless goodwill, unhealthy curiosity "[9].

This wholly unsuitable reception paralyzes the natural operation of the hospital. The basic principle of Emergency Plans is, therefore, to provide better welcoming to these epidemic victims while disposing security to the already hospitalized patients progressively and possibly ensuring some usual emergencies functioning. In practice, how to deal with the raising groups of victims?

In this paper, we are particularly interested in increasing the reception capacity via intercoordination networks linking several regional hospitals and guaranteeing the safety of the hospitalized persons in each hospital.

\subsection{The increase of reception capacity [9]}

The White Plan then defines how to increase hospital capacity. Starting from a census as quickly as possible of the existing means (staff, beds, operating rooms, laboratories, etc.) at the time of the alert, several procedures kickoff:

- Keep staff on site especially if an event occurs during a team change.

- Lightening plus deprogramming the activities of operating theaters, radiology departments, and laboratories.

- Move patients whose stable conditions demand less involved services, even towards other institutions.

- Recall staff by:

- A multiplication-tested system.

- Graduation according to the projected duration.

- A list of updating, confidential, and accessible contacts 'information.

- A rally to their service or a specific decontamination point.

- Effective functioning of the staff children nursery.

In this work, our studies are geared towards emergency decision support systems. Although much research has been done in this area, to our knowledge, none of them has really focused on the collaborative use of telemedicine for emergency decision support systems, especially its uses during evacuation and between health centers structures 
that save time and save lives during crisis management. The success of crisis management is linked not only to a well-developed strategy. The main objective of our methodology is to build a knowledge base updated regularly by the negative selection algorithms that will improve the decision making in the emergency department.

\section{Overview of the AIS techniques}

\subsection{Basic concepts}

The Artificial Immune System field, being inspired from the natural immune system of several species, helps ambitious practitioners to develop systems that operate within environments facing similar constraints that natural immune system deals with biologically. In this context, De Castro and Timmis define the AIS as "the adaptive systems, inspired by the theories of the immunology, as well as the functions, the principles and the immune models, in order to be applied to the resolution of problems..." [10].

The immunity is subdivided into two distinct systems: the innate immune system and the adaptive immune system. The adaptive immune system has three principal processes: negative selection, clonal selection and immune network [11]. Whereas, Natural Dendritic Cells are the link between the innate and adaptive immune system.

\subsection{Negative selection}

The purpose of negative selection is to provide tolerance for self-cells, wherein, the thymus is a gate against the non-self-antigens, and the $\mathrm{T}$ cells representing non-self-antigens, are destroyed in this organ. All the T-cells retiring of the thymus and circulating in the body are set tolerantly towards the self [12].

\subsection{Clonal selection}

The clonal selection algorithm is used by the natural immune system to define the basic features of an immune response of an antigenic stimulus [13].This algorithm achieves the idea of only the cells that capable to recognize the antigens are selected to proliferate against the intrudes. These selected cells are subjects to affinity mature processes, which improves their selective affinity of the antigens. They include detectors in their clusters indeed. These readers can detect specific antigens in variate stages of the clonal selection (For more details consult the article [14]).

\subsection{Immune network}

The immune network theory was first proposed by the researcher Jerne [15], who stated that an artificial immune network is a bio-inspired informatic model that uses the ideas/concepts of the immune network theory, and, mainly, the interaction between B-cells and the cloning process. In fact, it receives an antigen as an intruder and, then, it sends back an immunized network comprising the B-cells able to adjust the disturbances. Hence, the immune network process is similar to the clonal selection, except that there exist mechanisms of deletion that destroy the cells having certain inceptions of affinities amidst one another.

\subsection{Dendritic Cells (DCs)}

The Dendritic Cells Algorithm is a secondgeneration algorithm based on an abstract model of natural dendritic cells (DCs) [16]. It was first introduced to the mathematical field in 2005 [17]. Indeed, natural DCs are parts of the innate immune system. They are responsible for the initial pathogen detection that acts as a vital link between the innate and adaptive immune systems.

Besides, the clonal selection algorithms mostly used as optimizing algorithms. They use a lower amount of classifications indeed. Thus, the artificial immune systems algorithms used for classification are considered as classifiers since they combine the output of many simple classifiers all together. Overall, the clonal selection principles were first achieved in 1959 [18].

\subsection{Training methods [19]}

The T-cells and B-cells are the two types of cells involved in order to recognize present pathogens. The population of these present cells in the bloodstream is responsible for recognizing and destructing the pathogens. This population acts collectively indeed. It can identify new pathogens using two training methods which are the negative and clonal selections. By activating the process of negative selection, the natural immune system (NIS) is capable to protect the tissues of the host organism from being attacked by the host's own immune system. Naturally, some cells generate detectors efficient in identifying proteins that exist on the surface of the cells. These detectors, so-called "antibodies", are randomly created, and before the cells become fully mature, they are "tested" in the thymus. This thymus is an organ located behind the sternum, and it is able to destroy any immature cells that identify the tissues of the organism as "non-self" 
[19]. Hence, the process of negative selection maps the negative space of a given class as such the given examples of the "self" class. Historically, the negative selection algorithm firstly appeared in 1994 [20]. By adopting this clonal selection process, the NIS is able to adjust itself in order to provide the most efficient response against pathogens' attacks. This clonal selection happens when a cell detector finds an already seen pathogen in the organism, herein, it clones itself, then starts the immune response. In fact, the cloning process introduces small variations in the pattern that the cell detector recognizes. The number of the clones created by a cell detector is proportional to the new pathogen cell "affinity". It is a measurable manner to detect the extent to which the cell matches the pathogen. The amount of variation allowed in the clones is negatively proportional to the affinity-the cells with the most affinities are mutated less. The clonal selection algorithms are similar to the natural selection systems, and the clonal selection algorithm is, therefore, similar to the genetic algorithms basing on natural selection [21]. Nevertheless, clonal selection algorithms have fewer parameters than genetic algorithms and, potentially, they do not require complex functioning operations. Thus, the clonal selection algorithms are mostly used as optimizing algorithms, and few of them adopted in the classification context. Ever since, the clonal selection principles previously appeared in 1959 [22], the artificial immune systems algorithms applied them for classifications, and they are considered to being classifiers - they combine the output of many simple classifiers.

\section{Analysis of arrival patients}

Several works stated the management of the sliding flow of the random arrivals to hospitals based on different methodologies. In this regard, Tandberg and Qualls used three statistical methods: the moving average and two seasonal decomposition methods. They predict the Emergency Department (ED) presentations number at any time of the week in the University Hospital of New Mexico [23]. Rotstein and other researchers developed a statistical model of emergency service in a hospital located in Israel [24].

Abdel-Aal and Mangoud used two univariate time-series analyses to modelling and predicting the monthly volume of patients during eleven-yearperiod (1986-96) at family and community medicine primary health care clinic of King Faisal University, Al- Khobar, Saudi Arabia [25]. Others scholars adopted Box-Jenkins models to estimate the daily emergent admissions, and the number of emergencies often occupied beds at Bromley Hospitals NHS Trust in the United Kingdom [26]. Jones, Joy, and Pearson studied ED models at a hospital in Tenerife, Spain. Their analysis was based on time-series of ED presentations number per-hour all along six-year-period (1997-2002). The authors divided the time-series models into linear and nonlinear models [27].

Few studies explored the use of knowledgebased-data articulating on the previously achieved solutions and past scenarios in order to make suitable decisions covering the massive flow of patients. Our work will present a proactive approach to solving this problem.

\section{Triage of patients in the emergency department}

A distinction was made among scales of available patients for triage at the emergency department level. Five classification levels of severity of the arrived patients at the Emergency Department (ED). Each level assigned weightings according to its severity. We cite the setting tools available as follows:

The Emergency Severity Index (ESI) is a fivepoint-score indicator developed by American research agency formerly known as the Agency for Healthcare Research and Quality. This validated score bore several modifications making it possible to obtain the current version in 5 points $[28,29]$. A score of 1 , indicates severe and unstable patient, corresponds to immediate management. A patient with a score of 5 is stable and does not require urgent care.

Another sorting ratio is the Manchester Triage Scale (MTS). It is developed in 1996. The study demonstrates that it can detect severe patients [30]. Subject to good use, including the training of personnel, MTS has good sensitivity. We detect patient levels from MTS1 to MTS5.

Also in Canada, the computerized sorting scale known as the Canadian Emergency Department (CRTC) [31, 32] was introduced in 1998 and it is widely adopted in the US. It takes into account the speed of implementation of the care and their reassessment time to adopt the consumption of care. It relies on a standardized list of reasons for consultation with the concept of determinant called the first and second order CIMU levels are distinguished from 1 to 5 .

It is, for this reason that an evaluation of the relevant trace according to three Levels was chosen:

- Level one: urgent patients 
- Level two: moderately urgent

- Level three: non-urgent patients

\section{Proposed filtering method}

Counting the constraints, problems presented in the introduction and on the basis of the AIS techniques negative selection and clonal selection adopted in this section, we will describe our proactive system architecture and our first filtering algorithm.

\subsection{System overview}

The main objective of our work is to develop a vital supporting tool for hospital decision-makers to strengthen the quality of their decisions whenever they face the massive flow of patients. The fundamental idea is to detect traces in the database and help executives by identifying bad scenarios utilizing AIS techniques, especially, negative and clonal selection. The analogy between the principle of the natural immune system and the problem as proposed above has prompted us to develop our system (see Table 1).

\subsection{Metrics distance}

A distance metric is a function that measures the similarity in-between two vectors: $x i=\left[x_{i l}\right.$, $\left.x_{i 2}, \ldots, x_{i D}\right]$ and $x i=\left[x_{j 1}, x_{j 2}, \ldots, x_{j D}\right]$. It yields a nonnegative real number and represents the degree of discrepancy between the two data points [33].

Among a large number of distance metrics proposed in the literature, the famously used metric is still the Euclidean distance. It was Euclid who established it before two thousand years gone by. Besides, another lengthy applied metric is the Manhattan one, which is also known as the cityblock distance [33].

Table 1. Analogy between the natural immune system principle and the developed system

\begin{tabular}{|c|c|}
\hline $\begin{array}{c}\text { Natural Immune } \\
\text { System }\end{array}$ & $\begin{array}{c}\text { Artificial Immune System } \\
\text { applied in our Hospital } \\
\text { emergency context }\end{array}$ \\
\hline $\begin{array}{l}\text { Self (antibody) } \\
\text { Non-self (antigen) } \\
\text { Lymphocyte (B- and T- } \\
\text { cell) } \\
\text { Detect the antigen } \\
\text { Cloning } \\
\text { memorization }\end{array}$ & $\begin{array}{l}\text { Relevant trace } \\
\text { Irrelevant trace } \\
\text { Detectors } \\
\text { Detect the irrelevant trace } \\
\text { Cloning and update the self- } \\
\text { data }\end{array}$ \\
\hline
\end{tabular}

We will explain the Manhattan distance choice of data based analysis articulating on a comparative study among various methods in terms of efficiency as follows.

\subsection{Choice of Manhattan distance}

For Scholars as Noel and Bernardete performed a work that analyzed the impact of the distinct distance Metrics in instance-based learning algorithms [34]. Notably, they examined the nearest neighbor algorithm (NN), and the Incremental Hypersphere Classifier (IHC) algorithm, which was proved to be effective of large-scale problems recognition and e-learning. They provided a detailed empirical assessment on fifteen datasets of several sizes and dimensions. Statistically, they showed that the Euclidean and Manhattan metrics produce significant results in the case of wide-range problems. However, grid search methods are often desirable to determine the best matching metric depending on the problem and the algorithm. They concluded that the Manhattan distance is preferred, in particular for large datasets, since it is less computationally demanding. This is what prompted us to adopt this approach.

\section{Methodology of matching with Manhattan distance}

\subsection{Definition of the problem}

The problem of supervised learning classification is defined in this sectionby the researchers. Giving a set of data solutions in a knowledge base comprising pairs of inputs and outputs:

$$
S=\left\{\left(t_{1}, y_{1}\right),\left(t_{2}, y_{2}\right),\left(t_{3}, y_{3}\right), \ldots,\left(t_{n}, y_{n}\right)\right\}
$$

Where $T_{i}$ is a vector of parameter values in dimension space $(S)$ :

$$
t_{i} \in T
$$

The function that maps each vector $T_{i}$ into Vector space to a class in the set $Y$, where:

$$
T_{i} \in Y
$$

The objective of a learning algorithm [16], is to construct a function $F$ that approaches a function $E$, where $F$ is the real function which classifies an input vector in $T$ in a $Y$-category described as follows:

$$
F(t): T \rightarrow Y
$$


To test our model, we use sets of test data $T$ from an already established knowledge base:

$$
\begin{aligned}
& T_{i}=\left\{t_{1}, t_{2}, t_{3}, \ldots \ldots . . t_{n}\right\} \\
& T_{j}=\left\{t_{1}, t_{2}, \ldots \ldots \ldots . . . t_{n}\right\} \\
& W=\left\{w_{1}, w_{2}, \ldots \ldots . w_{n}\right\}
\end{aligned}
$$

The $W$ vector is the associated weight vector to $T$ participates in the decision making.

The Manhattan distance is as the following formula indicates [34]:

$$
d\left(T_{i}, T_{j}\right)=\mid \sum\left(\left(t k\left(T_{i}\right)-t k\left(T_{j}\right)\right) \mid\right.
$$

The process of preferences is given as follows:

$$
\operatorname{Min} d\left(T_{i}, T_{j}\right)=\operatorname{Min} \frac{\sum((t k(T i)-t k(T j)) \cdot w i}{\sum w i}
$$

\subsection{Optimization framework}

In a multi-hospital environment, it is more convenient to transfer the non-emergency patients towards others providing resources hospitals instead of tolerating the not satisfied demands or longwaiting-time within it. As a result, finding the appropriate level of resources, taking into account the patient transfer hypothesis, will considerably reduce overcrowding in hospitals. In this section, the optimization model considers the component capacity of hospitals. The notations bellow define mathematical model sets of parameters:

- $\quad i, j$ : Hospital and demand area indices.

- $t$ :Time indices.

- $l$ :Patient emergency type indices (1: emergency patients; 2: medium urgent; 3 : not urgent).

- H:Total number of hospitals.

- $\quad L$ : Variants type of the patient.

- $c_{i}$ : Cost of increasing a unit of capacity at the hospital $i$.

- $\quad d_{i}$ : Overtime cost at the hospital $i$.

- $x_{i}$ : Capacity considered for hospital $i$.

- $n_{i, \mathrm{j}}$ : Non-emergency patients number $(1=3)$ sent from $i$ hospital to $j$ hospital.

- $d_{i, l, t}:$ Number of 1 type discharged patients from $i$ hospital at $t$ time.

- $\quad k_{i, t}$ : Available capacity in $i$ hospital at $\mathrm{t}$ time.

- $P \quad 2 \quad 22 \quad 22 \quad t$ : Number of 1 type patients admitted to $i$ hospital at $t$ time.

$$
\operatorname{Min} \sum_{i \in H} c_{i} x_{i}+\sum_{i \in H} \sum_{j \in H} z_{i} j n_{i, j}
$$

Capacity constraints $(R)$

All time available capacity equals the previous capacity changed by accepted and discharged patients.

$$
k i, t=k_{i, t-1}-\sum_{l \in L} p_{i, l, t-1}+\sum_{l \in L} d_{i, l, t}
$$

The total number of accepted patients cannot exceed the available capacity.

$$
\sum p_{i, k, t}, \leq k_{i, t} \quad \forall i \in H
$$

Available capacity should be equalto or less than assigned resources to that shift.

$$
k_{i, t} \leq x_{i} \forall i \in H
$$

Transfer patient constraint should be less than the transfer limit of origin hospital and destination hospital available capacity.

$$
n_{i, j, t} \leq k_{j, t, j} \quad \forall i, j \in H .
$$

In the following section, we present the architecture of our system as well as a description of the algorithms.

\section{System architecture}

As indicated by several authors, the traces treatment passes through three main stages: collection, analysis and exploitation. We work on the second and last stage precisely. Indeed, in the second step (i.e. trace analysis), the traces collected in the first step are filtered using the Manhattan distance [34]. In the last step, the objective is to supply hospital decision-makers by suitable traces and to keep all relevant learning traces in the knowledge base.

\subsection{Collection of traces}

The system brings the actions taken by hospital decision-makers all together. The recorded traces on the Knowledge Base are from the User-system interaction. In addition, other traces may occur from other servers.

\subsection{Analysis of traces}

Trace form: A new dataset is created when the 


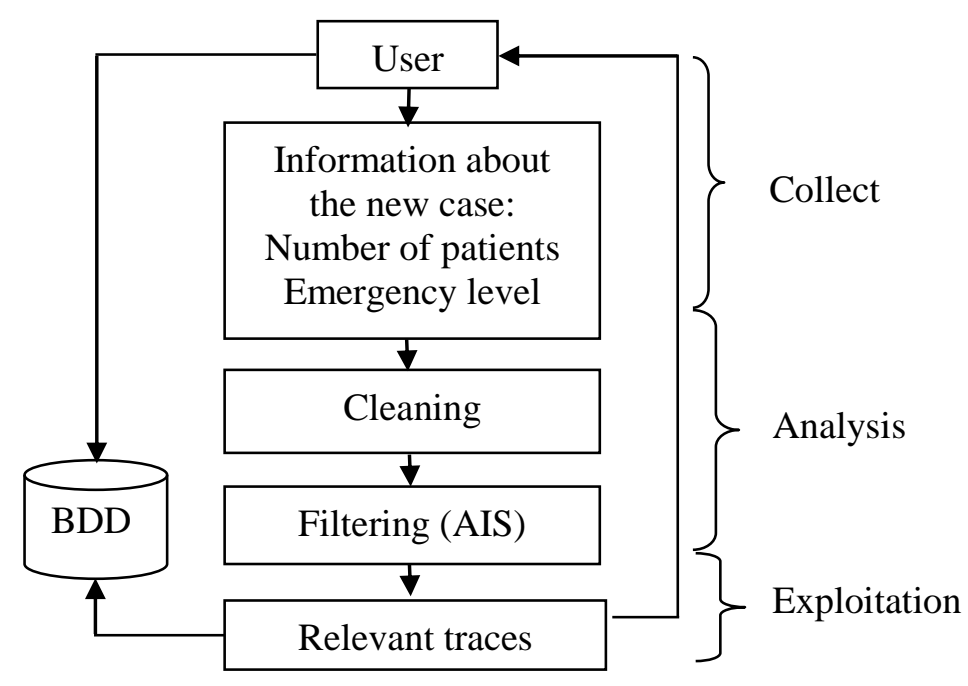

Figure. 1 System architecture

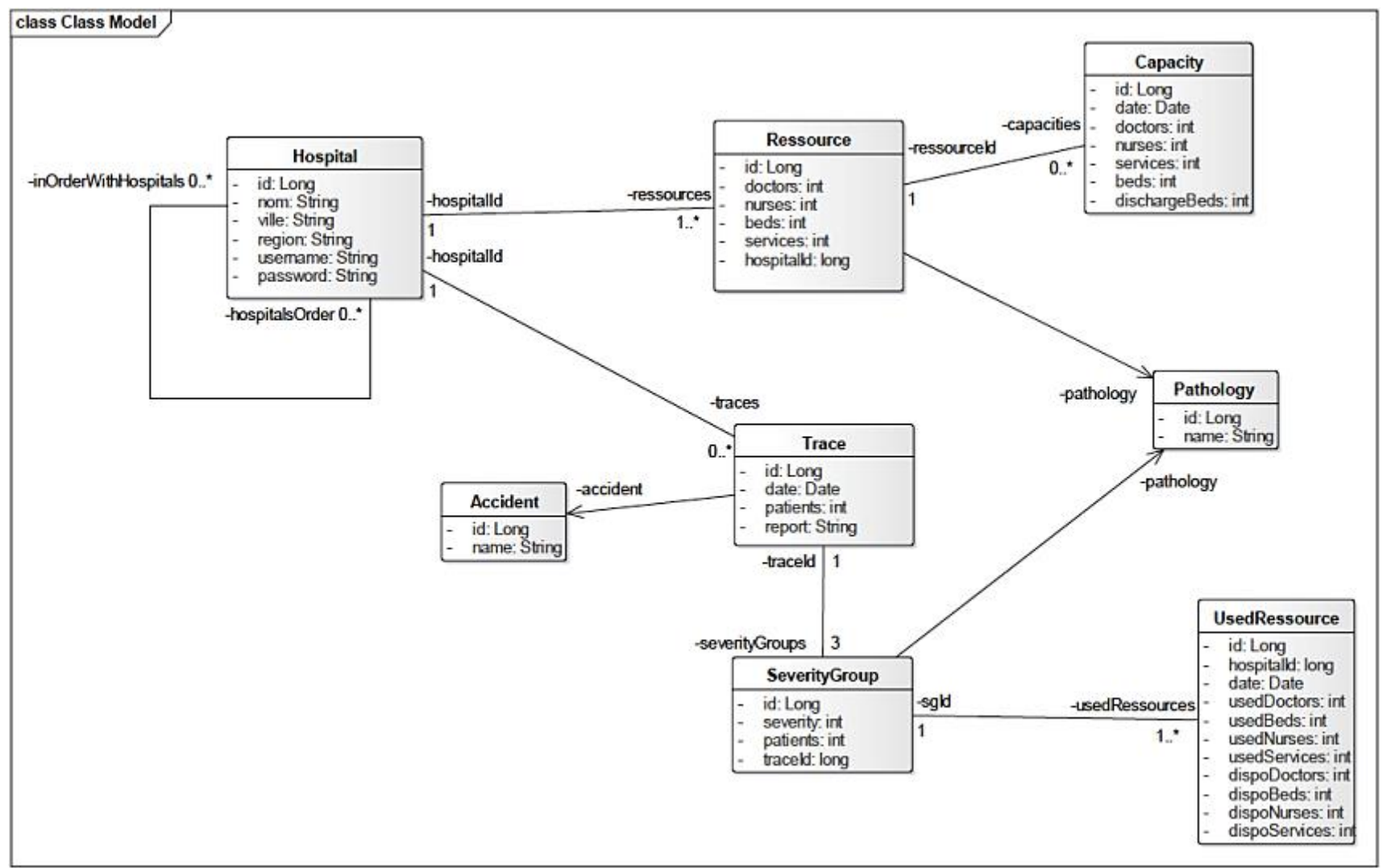

Figure. 3 The global architecture

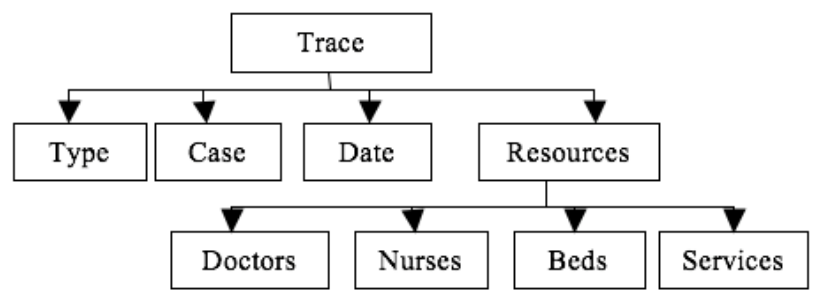

Figure. 2 Trace format traces are reformulated according to the proposed format. The general format of the trace is defined as follows (Fig. 3):

- $T=\left\{\mathrm{t}_{1}, \mathrm{t}_{2}, \mathrm{t}_{3}, \mathrm{t}_{4}, \ldots\right\}$

- $t$ : type of cases, which is $(t)$ characterized by the following 4-tuple:

- $t=\{T, C, D, R\}$

- $T$ : Type. 
- $\quad C$ : case is the number of patients and their pathology.

- $\quad D$ : Date.

- $R$ : Resources, where- $R=\{D o c, N, B, S\}$

Cleaning: to eliminate the noise (the number of patients that did not correspond to the case entered), an algorithm of cleaning of the traces is proposed (see Algorithm 1).

\begin{tabular}{|l|}
\hline Algorithm1: Cleaning traces \\
Input: $\mathrm{T}=\mathrm{a}$ set of traces, $\mathrm{C}$ : case \\
Output:CT $=$ a set of cleaned traces \\
ND: Nearest distance \\
NT: set of nearest $\mathrm{T}$ \\
Begin \\
For all (trace $t \in \mathrm{T})$ then \\
Ct: case of trace. \\
D: $\mathrm{d}(\mathrm{Ct}, \mathrm{C})=|\mathrm{C}-\mathrm{Ct}|$ \\
If $(\mathrm{ND}$ is null or $\mathrm{D}<\mathrm{ND})$ then \\
$\quad \mathrm{ND}=\mathrm{D}$ \\
$\quad \mathrm{t} \in \mathrm{NT}$ \\
Else if $(\mathrm{d}=\mathrm{ND})$ \\
$\quad \mathrm{t} \in \mathrm{NT}$ \\
End for \\
End $\quad$ \\
\end{tabular}

Filtering: in order to automatically detect the bad scenarios already recorded against the real case entered by the hospital decider, we used an algorithm to filter traces and keep only the relevant elements that will present the relevant traces for the case given by the manager.

\section{Computational results}

Global architecture of work entities to guarantee agility of our system, we applied an approach via work components. We present the global architecture of the ${ }^{2} 1$ entities Fig. 3.

In favour of validating our idea, we have set up a subsystem called Emergency Management (EM). It aims to filter all the traces on the database to display only the relevant traces of the case entered on the interface.

The projected system searches the corresponding case solution on the database according to the available resources, and in collaboration networks with other databases corresponding to the regional hospitals.

The selecting resources process takes into account the host hospital available resources in realtime, and at the same time, it coordinates with other regional hospitals.

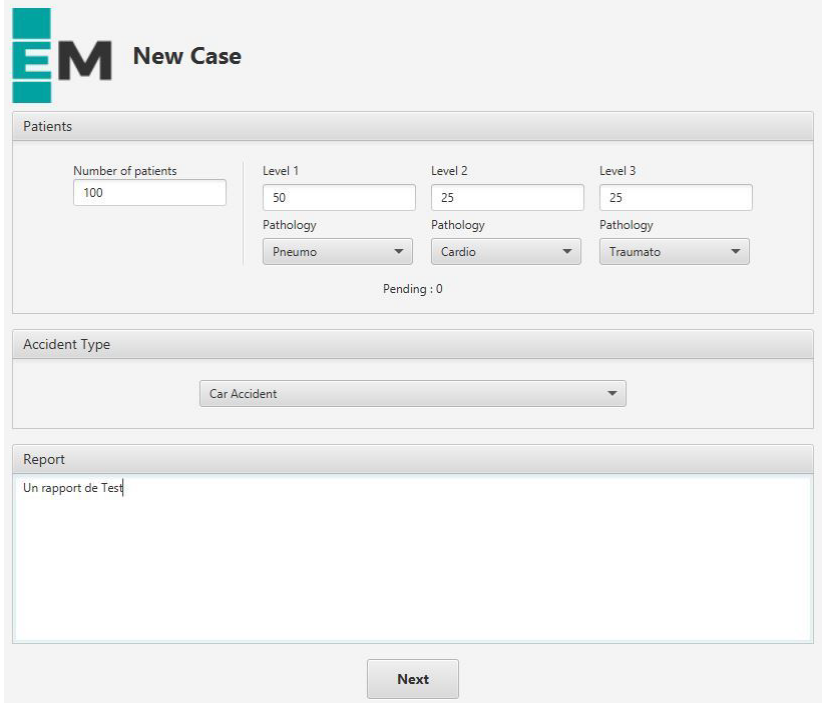

Figure. 4 The results of the proposed algorithm for detecting relevant solutions

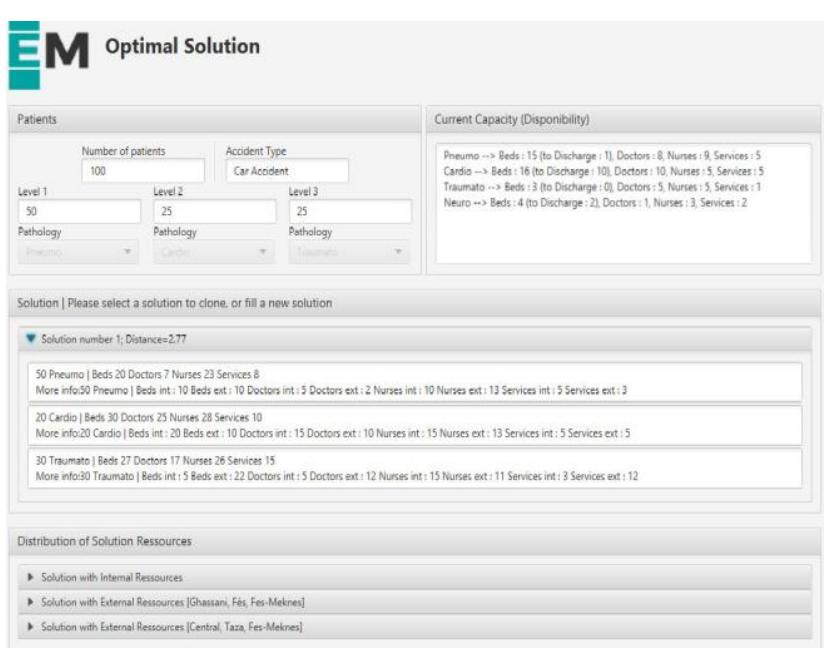

Figure. 5 Displaying optimal solutions

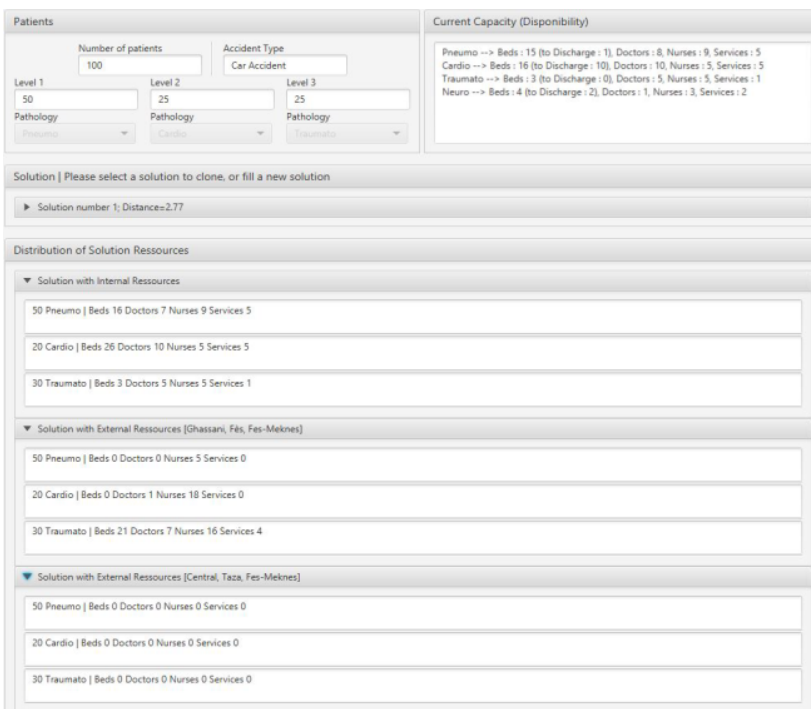

Figure. 6 The distribution of patients between regional hospitals according to their level of urgency 
Table 2. Sample of study in the database

\begin{tabular}{|c|c|c|c|c|}
\hline Hospital & $\begin{array}{l}\text { Patients Number } \\
\text { by Case }\end{array}$ & $\begin{array}{l}\text { Traces Number by } \\
\text { Patients Number }\end{array}$ & $\begin{array}{l}\text { Severity Groups } \\
\text { Number by Trace }\end{array}$ & $\begin{array}{l}\text { Utilized Resources Number } \\
\text { by Group of Severity }\end{array}$ \\
\hline . & $\begin{array}{l}60 \\
70 \\
80 \\
90 \\
100 \\
110 \\
120 \\
130 \\
140 \\
150 \\
160 \\
170 \\
180 \\
190 \\
200 \\
210 \\
220 \\
230 \\
240 \\
250\end{array}$ & $\begin{array}{l}\text { Over } 50 \text { traces by } \\
\text { patients' number with } \\
\text { different combinations }\end{array}$ & 3 & $\begin{array}{l}\text { Min: } 1 \text { (internal resources) } \\
\text { Max: } 3 \text { ( } 1 \text { internal resources + } \\
2 \text { external resources) }\end{array}$ \\
\hline $\begin{array}{l}\text { Total of a } \\
\text { Hospital }\end{array}$ & Total of Cases 20 & $\begin{array}{c}\text { Total of Traces more } \\
\text { than } 1500\end{array}$ & $\begin{array}{l}\text { Total of Groups } \\
\text { more than } 3000\end{array}$ & With 9000 \\
\hline
\end{tabular}

The priority selection of the resources of each hospital is given considering the budgetary constraint of patient transfers, the logistical constraints as well as the constraint capacity of each hospital.

The figures 5 and 6 show the results obtained from our system. The patients' distribution results are shown according to their urgency level bearing the logistical, capacitive and budgetary constraints.

We adapted and applied AIS techniques in a hospital system. The main objective of our work is to provide relevant traces for decision-makers (which go back to the scenarios of the cases already passed by the emergency department) and afford them the most appropriate elements. The objective lurking beneath is to improve real-time scenarios and supply hospital decision-makers with a minimal helpful set of traces. The filtering process integrates AIS techniques in which the negative and clonal selections are associated - the negative selection is applied to detect relevant traces, and the clonal selection helps to update the original database. The developed subsystem detects all suited sequences of actions and recommends decision-makers to find the right decision.

In this paper, the principles of the white plan were computerized to bring up real-time responses to the hands of hospital decision makers for distributing patients granting their urgency level. The coordination in-between hospitals are admitting in logistical, capacitive and budgetary constraints, and guaranteeing the safety of the already hospitalized patients in the hospital. All told to sum up the objective of this first part.

We are going to fill the white plan boundaries in our system to provide an 'all-risks' strategy in emergencies.

\subsection{Database alimentation}

The database was alimented from scenarios randomly generated, in which we selected in the following example, a sample of 20 cases. Then, for each number of patients, there are 50 traces of every single number with different gravity degrees and different pathologies aiming to prove the results of our filtering algorithms, as well as to memorize the findings.

To check the approach performance, we dispose of an application that employs a database of 10,000 cases where the results of the accomplishment displayed in Table 2.

After performing the program of a chosen sample for endorsing our approach, we gave the execution time in every single case: 
Table 3. The results of executional timing during the solution research proves over the collaboration among databases

\begin{tabular}{|c|c|c|}
\hline Trace & Maximal Hospital Participants & Time of Execution \\
\hline $\begin{array}{c}\text { Patients }=60-\text { Cardiac (15), Neurotic (15), } \\
\text { Nephrotic (30) }\end{array}$ & 1 (Internal only) & $\begin{array}{l}\text { Load }=1341 \mathrm{~ms} \\
\text { Cleaning }=2 \mathrm{~ms} \\
\text { Filtering }=1 \mathrm{~ms} \\
\text { Distribution }=1 \mathrm{~ms} \\
\text { Total }=\mathbf{1 3 4 5 m s}\end{array}$ \\
\hline $\begin{array}{c}\text { Patients }=70-\text { Orthopedic (20), Neurotic (30), } \\
\text { Pneumonic (20) }\end{array}$ & 1 (Internal only) & $\begin{array}{l}\text { Load }=1341 \mathrm{~ms} \\
\text { Cleaning }=2 \mathrm{~ms} \\
\text { Filtering }=1 \mathrm{~ms} \\
\text { Distribution }=1 \mathrm{~ms} \\
\text { Total }=\mathbf{1 3 4 5 m s}\end{array}$ \\
\hline $\begin{array}{c}\text { Patients }=80-\text { Neurologic (40), Cardiac (10), } \\
\text { Pneumonic (30) }\end{array}$ & 1 (Internal only) & $\begin{array}{l}\text { Load }=1341 \mathrm{~ms} \\
\text { Cleaning }=2 \mathrm{~ms} \\
\text { Filtering }=1 \mathrm{~ms} \\
\text { Distribution }=1 \mathrm{~ms} \\
\text { Total }=\mathbf{1 3 4 5} \mathrm{ms}\end{array}$ \\
\hline $\begin{array}{c}\text { Patients }=90-\text { Cardiac (50), Orthopedic (10), } \\
\text { Pneumonic (30) }\end{array}$ & 1 (Internal only) & $\begin{array}{l}\text { Load }=1341 \mathrm{~ms} \\
\text { Cleaning }=2 \mathrm{~ms} \\
\text { Filtering }=1 \mathrm{~ms} \\
\text { Distribution }=1 \mathrm{~ms} \\
\text { Total }=\mathbf{1 3 4 5 m s}\end{array}$ \\
\hline $\begin{array}{c}\text { Patients }=100-\text { Traumatic (50), Orthopedic (5), } \\
\text { Nephrotic (45) }\end{array}$ & $2(1$ Internal + 1external $)$ & $\begin{array}{l}\text { Load }=1327 \mathrm{~ms} \\
\text { Cleaning }=2 \mathrm{~ms} \\
\text { Filtering }=1 \mathrm{~ms} \\
\text { Distribution }=8 \mathrm{~ms} \\
\text { Total }=\mathbf{1 3 3 8 m s}\end{array}$ \\
\hline $\begin{array}{c}\text { Patients }=110-\text { Cardiac }(55), \text { Neurotic }(15), \\
\text { Nephrotic }(40)\end{array}$ & $2(1$ Internal +1 external $)$ & $\begin{array}{l}\text { Load }=1327 \mathrm{~ms} \\
\text { Cleaning }=2 \mathrm{~ms} \\
\text { Filtering }=1 \mathrm{~ms} \\
\text { Distribution }=8 \mathrm{~ms} \\
\text { Total }=\mathbf{1 3 3 8 m s}\end{array}$ \\
\hline $\begin{array}{c}\text { Patients }=120-\text { Orthopedic }(90), \text { Traumatic } \\
(5), \text { Pneumonic }(25)\end{array}$ & $2(1$ Internal + 1external $)$ & $\begin{array}{l}\text { Load }=1327 \mathrm{~ms} \\
\text { Cleaning }=2 \mathrm{~ms} \\
\text { Filtering }=1 \mathrm{~ms} \\
\text { Distribution }=8 \mathrm{~ms} \\
\text { Total }=\mathbf{1 3 3 8 m s}\end{array}$ \\
\hline $\begin{array}{c}\text { Patients }=130-\text { Cardiac }(85), \text { Neurotic }(30), \\
\text { Gastro }(15)\end{array}$ & $2(1$ Internal +1 external $)$ & $\begin{array}{l}\text { Load }=1327 \mathrm{~ms} \\
\text { Cleaning }=2 \mathrm{~ms} \\
\text { Filtering }=1 \mathrm{~ms} \\
\text { Distribution }=8 \mathrm{~ms} \\
\text { Total }=\mathbf{1 3 3 8 m s}\end{array}$ \\
\hline $\begin{array}{c}\text { Patients }=140-\text { Orthopedic (60), Traumatic (5), } \\
\text { Pneumonic (75) }\end{array}$ & $2(1$ Internal +1 external $)$ & $\begin{array}{l}\text { Load }=1327 \mathrm{~ms} \\
\text { Cleaning }=2 \mathrm{~ms} \\
\text { Filtering }=1 \mathrm{~ms} \\
\text { Distribution }=8 \mathrm{~ms} \\
\text { Total }=\mathbf{1 3 3 8 m s}\end{array}$ \\
\hline $\begin{array}{c}\text { Patients }=150-\text { Gastro (40), Orthopedic (95), } \\
\text { Neurotic (15) }\end{array}$ & $2(1$ Internal +1 external $)$ & $\begin{array}{l}\text { Load }=1327 \mathrm{~ms} \\
\text { Cleaning }=2 \mathrm{~ms} \\
\text { Filtering }=1 \mathrm{~ms}\end{array}$ \\
\hline
\end{tabular}




\begin{tabular}{|c|c|c|}
\hline Trace & Maximal Hospital Participants & Time of Execution \\
\hline & & $\begin{array}{l}\text { Distribution }=8 \mathrm{~ms} \\
\text { Total }=\mathbf{1 3 3 8} \mathbf{m s}\end{array}$ \\
\hline Patients $=160-$ Cardiac (80), Traumatic (10), & $2(1$ Internal +1 external $)$ & $\begin{array}{l}\text { Load }=1327 \mathrm{~ms} \\
\text { Cleaning }=2 \mathrm{~ms} \\
\text { Filtering }=1 \mathrm{~ms} \\
\text { Distribution }=8 \mathrm{~ms} \\
\text { Total }=\mathbf{1 3 3 8 m s}\end{array}$ \\
\hline $\begin{array}{c}\text { Patients }=170-\text { Orthopedic }(70), \text { Traumatic } \\
(10), \text { Neurotic }(90)\end{array}$ & 3 (1 Internal +2 externals $)$ & $\begin{array}{l}\text { Load }=1462 \mathrm{~ms} \\
\text { Cleaning }=2 \mathrm{~ms} \\
\text { Filtering }=1 \mathrm{~ms} \\
\text { Distribution }=6 \mathrm{~ms} \\
\text { Total }=\mathbf{1 4 7 3 m s}\end{array}$ \\
\hline $\begin{array}{c}\text { Patients }=180-\text { Gastro (50), Nephrotic (100), } \\
\text { Cardiac (30) }\end{array}$ & 3 (1 Internal +2 externals $)$ & $\begin{array}{l}\text { Load }=1462 \mathrm{~ms} \\
\text { Cleaning }=2 \mathrm{~ms} \\
\text { Filtering }=1 \mathrm{~ms} \\
\text { Distribution }=6 \mathrm{~ms} \\
\text { Total }=\mathbf{1 4 7 3 m s}\end{array}$ \\
\hline $\begin{array}{c}\text { Patients }=190-\text { Neurotic (50), Orthopedic (90), } \\
\text { Pneumonic (50) }\end{array}$ & 3 (1 Internal +2 externals $)$ & $\begin{array}{l}\text { Load }=1462 \mathrm{~ms} \\
\text { Cleaning }=2 \mathrm{~ms} \\
\text { Filtering }=1 \mathrm{~ms} \\
\text { Distribution }=6 \mathrm{~ms} \\
\text { Total }=\mathbf{1 4 7 3 m s}\end{array}$ \\
\hline $\begin{array}{c}\text { Patients }=200-\text { Cardio (50), Traumatic }(80), \\
\text { Gastro }(70)\end{array}$ & 3 (1 Internal +2 externals $)$ & $\begin{array}{l}\text { Load }=1462 \mathrm{~ms} \\
\text { Cleaning }=2 \mathrm{~ms} \\
\text { Filtering }=1 \mathrm{~ms} \\
\text { Distribution }=6 \mathrm{~ms} \\
\text { Total }=\mathbf{1 4 7 3 m s}\end{array}$ \\
\hline $\begin{array}{c}\text { Patients }=210-\text { Orthopedic }(90), \text { Nephrotic } \\
(25), \text { Neurotic }(95)\end{array}$ & 3 (1 Internal +2 externals $)$ & $\begin{array}{l}\text { Load }=1462 \mathrm{~ms} \\
\text { Cleaning }=2 \mathrm{~ms} \\
\text { Filtering }=1 \mathrm{~ms} \\
\text { Distribution }=6 \mathrm{~ms} \\
\text { Total }=\mathbf{1 4 7 3 m s}\end{array}$ \\
\hline Patients $=220-$ Cardiac (110), Traumatic (65), & 3 (1 Internal +2 externals $)$ & $\begin{array}{l}\text { Load }=1462 \mathrm{~ms} \\
\text { Cleaning }=2 \mathrm{~ms} \\
\text { Filtering }=1 \mathrm{~ms} \\
\text { Distribution }=6 \mathrm{~ms} \\
\text { Total }=\mathbf{1 4 7 3 m s}\end{array}$ \\
\hline $\begin{array}{c}\text { Patients }=230-\text { Orthopedic }(70), \text { Traumatic } \\
(90), \text { Gastro }(70)\end{array}$ & 3 (1 Internal +2 externals $)$ & $\begin{array}{l}\text { Load }=1462 \mathrm{~ms} \\
\text { Cleaning }=2 \mathrm{~ms} \\
\text { Filtering }=1 \mathrm{~ms} \\
\text { Distribution }=6 \mathrm{~ms} \\
\text { Total }=\mathbf{1 4 7 3 m s}\end{array}$ \\
\hline $\begin{array}{c}\text { Patients }=240-\text { Nephrotic }(165), \text { Gastro }(15), \\
\text { Pneumonic }(60)\end{array}$ & 3 (1 Internal +2 externals $)$ & $\begin{array}{l}\text { Load }=1462 \mathrm{~ms} \\
\text { Cleaning }=2 \mathrm{~ms} \\
\text { Filtering }=1 \mathrm{~ms} \\
\text { Distribution }=6 \mathrm{~ms} \\
\text { Total }=\mathbf{1 4 7 3 m s}\end{array}$ \\
\hline $\begin{array}{c}\text { Patients }=250-\text { Cardiac (50), Orthopedic (105), } \\
\text { Nephrotic (95) }\end{array}$ & 3 (1 Internal +2 externals $)$ & $\begin{array}{l}\text { Load }=1462 \mathrm{~ms} \\
\text { Cleaning }=2 \mathrm{~ms} \\
\text { Filtering }=1 \mathrm{~ms}\end{array}$ \\
\hline
\end{tabular}




\begin{tabular}{|l|l|l|}
\hline Trace & Maximal Hospital Participants & Time of Execution \\
\hline & & $\begin{array}{l}\text { Distribution }=6 \mathrm{~ms} \\
\text { Total }=1473 \mathrm{~ms}\end{array}$ \\
\hline
\end{tabular}

In the first example, the number of patients equals to 90, where, the looking solution was fulfilled in the local database, and among similar numbers with different degrees of gravity and pathologies.

In the second case, the number of patients equals to 60 , where, the searched solution process was due in two different databases which presented multiple similar scenarios of the same number of patients, but with different gravity degrees and pathologies.

The third case consisted of looking for the optimal solution retrieved from a single internal or Local database, and two external databases which represent the already chosen 2 external hospitals in this case. Likewise, the presence of a couple of similar scenarios, with different gravity degrees and pathologies, however.

Note: "lead-time" signifies the time to load information of the hospital and the hospitals that contribute of resources' distribution. That is performed one time while the application is running and it, broadly, reduces the constant demands on information from databases.

\section{Conclusions and discussions}

The anomaly detection is one feature of the AIS techniques. We adapted this feature to satisfy our concern, which is filtering and improving the hospital database knowledge. The bad scenario (or set of irrelevant traces) is the solution that will not fit the urgent requirements of the massive patient flow arriving at the emergency services of a hospital. We adapted and applied AIS techniques to supply hospital decision-makers with a supporting tool. The major ambition of our work is fairly presenting relevant traces to these administrators (which go back to their old solutions) and provide them with the relevant elements in order to satisfy their needs.

In the future, it would be interesting to use the idea for the management of EHR (electronic health records) in order to Detecting clinical pathways reflect the best evidence available in practice, indicating the order of intervention of the most widely applicable treatment and treatment regimen. We later propose a data-driven clinical practice development methodology to extract common clinical pathways from patient-centric electronic health record data that is compatible with clinical flow and facilitates patient care.

\section{References}

[1] A. Kellermann, "Crisis in the Emergency Department", New England Journal of Medicine, Vol.355, No.13, pp.1300-1303, 2006.

[2] M. K. Lindell, C. Prater, and R. W. Perry, Wiley pathways introduction to emergency management, Hoboken, NJ: Wiley, 2006.

[3] F. Harrou, F. Kadri, S. Chaabane, C. Tahon, and Y. Sun, "Improved principal component analysis for anomaly detection: Application to an emergency department", Computers \& Industrial Engineering, Vol.88, pp.63-77, 2015.

[4] F. Kadri, C. Pach, S. Chaabane, T. Berger, D. Trentesaux, C. Tahon, and Y. Sallez, "Modelling and management of strain situations in hospital systems using an orca approach", In: Proc. of International Conf. on Industrial Engineering and Systems Management, pp.1-9, 2013.

[5] F. Kadri, F. Harrou, S. Chaabane, and C. Tahon, "Time series modelling and forecasting of emergency department overcrowding", Journal of Medical Systems, Vol.38, No.9, pp.1-20, 2014.

[6] F. Harrou, Y. Sun, F. Kadri, S. Chaabane, and C. Tahon, "Early Detection of Abnormal Patient Arrivals at Hospital Emergency Department", In: Proc. of International Conf. on Industrial Engineering and Systems Management, 2015.

[7] F. Kadri, S. Chaabane, and C. Tahon, "A simulation-based decision support system to prevent and predict strain situations in emergency department systems", Simulation Modelling Practice and Theory, Vol.42, pp.3252, 2014.

[8] P. Carey, G. Cuthbert, R. Dang, B. Greystoke, A. McGregor, R. Oakes, and J. Wallis, "The North of England haemato-oncology diagnostic service (NEHODS): A more devolved and inclusive approach to integrated reporting facilited by an IT system (Haemosys) networked to local information management systems (LIMS) in all participating regional hospitals", British Journal of Haematology, Vol.173, No.1,pp.43-43, 2016.

[9] J. V.de Carvalho, Á.Rocha, and J.Vasconcelos, "Towards an Encompassing Maturity Model for 
the Management of Hospital Information Systems", Journal of Medical Systems, Vol.39, No.9, pp.99, 2015.

[10] C. Virenque, "Large Influx of Injured People in Hospital", Hôpital Purpan, pp.712-715, 2016.

[11] L. N. De Castro and J. Timmis, "Artificial immune systems: a novel paradigm to pattern recognition", Artificial Neural Networks in Pattern Recognition, Vol.1, pp.67-84, 2002.

[12] J. Timmis, A. Hone, T. Stibor, and E. Clark, "Theoretical Advances in Artificial Immune Systems", Theoretical Computer Science, Vol.403, No.1, pp.11-32, 2008.

[13] U. Aickelin and D. DasGupta, "Artificial immune systems", Search Methodologies, pp.375-399, 2005.

[14] L. N. De Castro, and F. J. Von Zuben, "The Clonal Selection Algorithm With Engineering Applications", In: Proc. of the Workshop on Artificial Immune Systems and Their Applications, Las Vegas, USA, 2000.

[15] L. N. De Castro and F. J. Von Zuben, "Learning and Optimization Using the Clonal Selection Principle", IEEE Transactions on Evolutionary Computation, Vol.6, No.3, pp.239-251, 2002.

[16] N. K. Jerne, "Towards a Network Theory of the Immune System", Ann Immunol, Vol.125, pp.373-389, 1974.

[17] J. Greensmith, U. Aickelin, and G. Tedesco, "Information Fusion for Anomaly Detection with the Dendritic Cell Algorithm", Information Fusion Journal, Vol.11, No.1, pp. 21-34, 2010.

[18] J. Greensmith, U. Aickelin, and S. Cayzer, "Introducing Dendritic Cells as a Novel Immune-Inspired Algorithm for Anomaly Detection", In: Proc. of the International Conference on Artificial Immune Systems, pp.153-167, 2005.

[19] M. Burnet, "The Clonal Selection Theory of Acquired Immunity", Nashville, Vanderbilt University Press, 1959.

[20] B. Schmidt, A. Al-Fuqaha, A. Gupta, and D. Kountanis, "Optimizing an artificial immune system algorithm in support of flow-Based internet traffic classification", Applied Soft Computing, Vol.54, pp.1-22, 2017.

[21] S. Forrest, A. Perelson, L. Allen, R. Cherukuri, "Self-nonself discrimination in a computer", In: Proc. 1994 IEEE Computer Society Symposium on Research in Security and Privacy, pp.202212, 1994.

[22] L.N. De Castro and F.J. Von Zuben, "Learning and optimization using the clonal selection principle", IEEE Transactions on Evolutionary Computation, Vol.6, No.3, pp.239-251, 2002.

[23] M. Burnet, "The Clonal Selection Theory of Acquired Immunity", Nashville, Vanderbilt University Press, 1959.

[24] D. Tandberg and C. Qualls, "Time series forecasts of emergency department patient volume, length of stay, and acuity", Annals of Emergency Medicine, Vol.23, No.2, pp.299306, 1994.

[25] Z. Rotstein, R. Wilf-Miron, B. Lavi, A. Shahar, U. Gabbay, and S. Noy, "The dynamics of patient visits to a public hospital ed: a statistical model", The American journal of emergency medicine, Vol.15, No.6, pp.596-599, 1997.

[26] R. Abdel-Aal and A. Mangoud, "Modeling and forecasting monthly patient volume at a primary health care clinic using univariate time-series analysis", Computer Methods and Programs in Biomedicine, Vol.56, No.3, pp.235-247, 1998.

[27] R. Abdel-Aal and A. Mangoud, "Modeling and forecasting monthly patient volume at a primary health care clinic using univariate time-series analysis", Computer Methods and Programs in Biomedicine, Vol.56, No.3, pp.235-247, 1998.

[28] S. Jones, M. Joy, and J. Pearson, "Forecasting demand of emergency care", Health Care Management Science, Vol.5, No.4, pp.297-305, 2002.

[29] D. R. Eitel, D. A. Travers, A. M. Rosenau, N. Gilboy, and R. C. Wuerz, "The emergency severity index triage algorithm version 2 is reliable and valid", Academic Emergency Medicine, Vol.10, No.10, 2003.

[30] P. Tanabe, R. Gimbel, P. R. Yarnold, and J. G. Adams, "The Emergency Severity Index (version 3) 5-level triage system scores predict ED resource consumption", Journal of Emergency Nursing, Vol.30, No.1, pp.22-29, 2004.

[31] M. W. Cooke and S. Jinks, "Does the Manchester triage system detect the critically ill?", Emergency Medicine Journal, Vol.16, No.3, pp.179-181.

[32] J. G. Jiménez, M. J. Murray, R. Beveridge, J. P. Pons, E. A. Cortés, J. B. F. Garrigós, and M. B. Ferré, "Implementation of the Canadian Emergency Department Triage and Acuity Scale (CTAS) in the Principality of Andorra: Can triage parameters serve as emergency department quality indicators?", Canadian Journal of Emergency Medicine, Vol.5, No.5, pp.315-322, 2003. 
[33] M. J. Bullard, B. Unger, J. Spence, E. Grafstein, and CTAS National Working Group, "Revisions to the Canadian emergency department triage and acuity scale (CTAS) adult guidelines", Canadian Journal of Emergency Medicine, Vol.10, No.2, pp.136142.

[34] R. O. Duda, P. E. Hart, and D. G. Stork, "Pattern Classification", $2^{\text {nd }}$ Edition: New York, Vol.55, 2001.

[35] N. Lopes and B. Ribeiro, "On the impact of distance metrics in instance-based learning algorithms", In: Proc. of Iberian Conf. on Pattern Recognition and Image Analysis, pp.48-56, 2015. 